\title{
A Study of the Post-Natal Growth and Remodeling of Bone
}

\author{
DONALD H. ENLOW \\ Department of Anatomy, The University of Michigan, \\ Ann Arbor, Michigan
}

Skeletal growth involves a variety of modeling processes which result in the rearrangement and recombination of histological components. Compact bone is formed as a composite of structural zones produced by the progressive accumulation of architectural changes. The purpose of this study is (a) to trace the sequence of specific remodeling changes during growth, and (b) to relate remodeling processes with corresponding patterns of microscopic structure.

\section{History}

Plato said that "God formed bone in this way. Sifting earth until it was pure and smooth, he kneaded it and moistened it with marrow, then he placed this mass in the fire, and next cast it into water, and again into the fire, and again into water, and so changing it from one into the other in turn, he made it of such a kind that it can not be dissolved by anything." Arnobius reported that a goddess is mentioned in ancient writings "who hardens and solidifies the bones in young infants." Riolan commented that the ancients invented a certain goddess to care for the bones, since the shape of the body depends on the skeleton. Hippocrates said that bones are produced by the burning and dryof fat (in the marrow). Both Aristotle and Galen believed that bone substance represents the "less noble" component of seminal residue which is not utilized elsewhere during the formation of the body from the seed. ${ }^{2}$ In the book of Ecclesiastes (11:5), it is said that "as thou knowest not what is the way of the spirit, nor how the bones do grow in the womb of her that is with child; even so thou knowest not the works of God who maketh all."

Vesalius realized the cartilaginous nature of early fetal bones, and his pupil, Fallopius, first recognized and described the epiphyseal plate of cartilage (Portal, 1770). Caspar Bartholin (1676) said that bones in the embryo are at first a fluid which is later filled with sinew, becomes cartilaginous, and then slowly acquires the hardness of bone. During the late 1600's and through the middle of the 1700's, standard textbook descriptions of bone growth maintained that a secretion of thin bone juice from the blood congeals first into transparent cartilage which is then transformed into soft bone, and which finally becomes hardened by deposits of saline-like nutrients ("succus nutritius"). This latter element was drawn from the blood either by heat, reduced diameter of vessels, by evaporation, or by rotational forces in the blood itself (Havers, 1691; Malpighi, 1743; Cheselden, 1733; Monro, 1763.) An interesting prelude to our modern understanding of bone growth was made as early as 1631 by Adrianus Spigeleius. He was apparently the first to suggest that the periosteum itself can produce new bone, and that bone increases in mass by a process of apposition. He also noticed the formative difference between skull bones (intramembranous) and long bones (endochondral). This latter observation was to be independently rediscovered at least three times in subsequent history (Nesbitt, 1736; Meckel, 1832, gives credit to Howship; Huxley, 1853, gives credit to Sharpey). Grew (1681), Leeuwenhoek (1693), and Malpighi (1743) compared the functional role of the periosteum in bone growth with that of the cambium in bark. Duhamel (1739-43) made the same analogy, and he termed the osteogenic component of the periosteum as the "cambium layer." Havers did not recognize the osteogenic function of the

${ }^{1}$ Supported by U.S.P.H.S. Grant D-1123.

2 The foregoing accounts have been taken from translations into the Latin by Albinus (1757). 
periosteum, and he introduced instead a controversial concept, based on interstitial growth, that has been argued for over 250 years. Hales (1727), by applying markers on a growing bone, discovered that growth in length is produced by an increase at its ends, rather than by internal expansion as proposed earlier by Havers. The staining of bone with madder was recorded by Lemnius in 1567 and by Mizaldus in 1566, but Belchier (1736) rediscovered this peculiar quality of madder and it soon became a useful tool in the hands of experimental investigators. Duhamel $(1739,1742$, 1743) found that this substance colors only that bone deposited during periods of active growth. He concluded, also, that the periosteum serves in an osteogenic capacity. In another experiment, Duhamel placed metal rings around the shafts of enlarging long bones, and he observed that these rings later became enclosed in the substance of the bone or within the marrow cavity. Although he had previously confirmed the concept of periosteal apposition, Duhamel could not explain these later findings on the basis of this process alone. He then concluded that bone grows by a process of expansion in addition to periosteal deposition, thus reviving the older concept of interstitial growth. Haller (1766) repeated these investigations, and he argued that blood vessels within the periosteum, and not this membrane itself, produced bone growth. John Hunter (1798) also reviewed and repeated these various pioneer studies. He recognized the critical problem that had troubled Duhamel, but he could not accept the hypothesis of interstitial growth. Hunter then formulated the fundamental concept that has become the basis for our present-day understanding of skeletal growth. He was the first to realize that bone growth involves two mutually related processes: outer deposition and inner resorption. Hunter thereby resolved the problem previously encountered by Duhamel. Hunter also was the first to state that "bone is constantly changing its matter," but like his contemporaries, he believed that bone removal was a function of the lymphatics. Brulle and Hugueny (1845), Flourens (1845), and Loven (1863) recognized the presence of resorption on a periosteal surface, rather than just on the endosteal margin, and they correctly associated this process with metaphyseal remodeling. They also realized that bone in the metaphysis can be produced by endosteal deposition.

Brash ('34) has summarized and discussed the established concepts and principles concerned with bone growth and modeling, including generalizations that the diaphyses of long bones grow in length by cartilage replacement at their ends only, that long bones grow in width by surface (sub-periosteal) apposition, and that interstitial expansion of bone does not occur. Information on differences in relative growth rates between different skeletal elements has been reported by Payton ('31). Lacroix ('45) made the observation that bone tissues in metaphyseal areas can be endosteal in origin, and he thus revived a concept introduced by Brulle and Hugueny and others a century earlier. Leblond et al. ('50), by the use of autoradiographic methods, established the significance of widespread endosteal bone growth as a basic process involved in the structure and shaping of the metaphysis. Leblond illustrated the sequence of remodeling changes which produce structural "funnels" within the cortex. Tomelin et al. ('53), also using autoradiographic techniques, reported remodeling processes concerned with the formation of shaft curvature, and they described the eccentric relocation of cortical bone produced by this mechanism. The structural arrangement and reconstruction of tissue components produced by this process, in addition to those discussed by Leblond, will be described in detail in the present study.

\section{MATERIALS AND METHODS}

Bone tissues from normal, untreated white rats and Rhesus monkeys were studied. These species were selected in view of their wide use as laboratory and experimental forms. In addition, bone samples from other species of representative vertebrate groups were examined. Routine dry ground sections were prepared by the use of a plastic-seal technique (Enlow, '54), and decalcified preparations were made using standard methods. Stained and decalcified sections were also prepared by a special technique which makes possible the 
preparation and examination of large numbers of samples without the need for embedding and sectioning with a microtome (Enlow, '61). In all, bone specimens from 108 monkeys and 83 rats were examined. Monkeys were grouped into relative age levels according to dental formulae. Bone tissues in the femur were studied in all of the animals, and bone from the tibia, radius, humerus, and mandible were examined in many of the individuals. Multiple, semi-serial sections were prepared throughout the length of each bone. Entire longitudinal sections of rat bones were made with the aid of the Gillings-Bronwill apparatus. ${ }^{3}$ One- per cent alizarin was administered to some of the white rats to establish reference marks in the growing bone. This procedure was used in order to trace the sequence and specific regional location of tissue changes involved in remodeling. Alizarin markers were also used to confirm the periosteal or endosteal nature of bone deposits.

Specific varieties of basic bone tissues were identified in different representative areas of each bone. The structural and developmental relationships of each bone type were determined. Combinations and progressive recombinations in the arrangement, pattern, and structure of these tissue types were then mapped according to sequential formation and particular regional location.

\section{OBSERVATIONS}

The developmental and structural interpretations of the observations described below are based on the classic scheme of progressive bone remodeling used by Kolliker (1853), Brash ('34), Weinmann and Sicher ('47), Leblond ('50), and Tomelin ('53). This generalized plan is illustrated in plate 1 . Note that the metaphysis is progressively reduced in diameter as the bone increases in length, and that metaphyseal bone is relocated in relative position to become part of the diaphysis. This process of metaphyseal remodeling involves resorption of periosteal surfaces in combination with apposition on the endosteal margin.

Cortical stratification. In all species examined, the compact bone substance of the cortex becomes stratified during growth and remodeling. This stratification is the result of (1) successive reversals in the direction of outward (periosteal) and inward (endosteal) growth, and (2) the formation of various kinds of bone tissues which are associated with different local growth circumstances. Growth reversals are produced by the increase-decrease-increase in diameter involved in metaphyseal to diaphyseal relocation following growth in length (figs. 1-3). Specific bone tissue types are characteristically located in particular and specific layers. The structural result is a compacta which is composed of conspicuous "zones," each of which can be interpreted in terms of developmental origin and specific location. While the overall shape and surface outlines of the growing bone remain constant, the substance of the compact bone itself becomes a structural conglomerate of reorganized growth levels (figs. 14, 19, 27).

During remodeling and reconstruction, pre-existing bone is not entirely removed or destroyed. Some, more or less, remains. This bone of older generations becomes enclosed or incorporated into the revised form as zones, layers, islands, or as a vestige of interstitial bone. Since new osseous deposits can form only on some surface exposure of a bone (endosteal, periosteal, cancellous, or the inner surface of a canal), the surface configuration of pre-existing bone determines the minute architectural patterns formed by subsequent deposits. The significance of these concepts to a developmental interpretation of structural arrangement will be seen in the following observations.

\section{Lamellar compaction of coarse cancellous bone}

This structural conversion produces a distinctive and characteristic type of compact bone tissue which is clearly recognizable in routine section preparations. If inward or endosteal growth, during metaphyseal reduction in diameter, proceeds into areas already occupied by coarse cancellous bone, the compaction of these cancellous trabeculae results in a cortex which is composed of coarse, irregular "whorls" or "convolutions" of compact bone (figs. 21 , 26). Or, depending on the density and

\footnotetext{
3 Bronwill Scientific, 3902 Russell Street, Box 3927, Rochester 10, New York.
} 
orientation of the trabeculae, isolated rods or sheets of bone may become enclosed (fig. 17). The original configuration of former trabeculae are recognizable. Thus, during inward growth involving periosteal resorption together with endosteal apposition, the thickness of the cortex is preserved, or even increased as the diaphysis is neared.

This frequently encountered tissue type is formed only by endosteal, never periosteal, apposition. The presence of such bone in any section is clear evidence that this specific region or zone was the result of inward growth. Following growth reversals, this particular bone tissue type becomes a distinctive zone enclosed by a different tissue variety (figs. 22, 27). Cortical bone composed partially or entirely of compacted coarse cancellous bone tissue is typically located towards the proximal and distal thirds of a long bone rather than in the mid-diaphysis. It is possible, thus, to identify the approximate location of any section by this feature. Such bone tissue is not extensively distributed in the middle third of the diaphysis since growth reversals have largely resulted in its removal and replacement.

\section{Lamellar compaction of fine cancellous bone}

The compaction of fine cancellous bone has been observed to take place during (1) the conversion of endochondral trabeculae into compact bone, (2) conversion of cortical non-lamellar bone present at birth into compact tissue, and ( 3 ) conversion of sub-periosteal, non-lamellar bone formed regionally during post-natal development.

Adjacent to the epiphyseal plate, progressive reduction in the diameter of the metaphysis involves endosteal lamellar deposition on the surface of pre-existing endochondral trabeculae. These trabeculae, containing distinguishing spicules of calcified cartilage matrix (fig. 16), are entombed as the cancelli become partially filled with concentric lamellae. The former spongy endochondral tissue has now been altered into compact bone and has been relocated from the medulla into the cortex. This bone type is easily recognized in stained, decalcified preparations (fig. 19C). Following elongation of the entire bone and subsequent growth reversals during metaphyseal-diaphyseal transition, compacted endochondral bone tissue becomes a distinct zone enclosed by layers of other tissue types and is re-positioned in the cortex at some distance from its original location near the epiphyseal plate (fig. 19). Remnants of old endochondral bone have been frequently observed in the cortical bone of adult rats and scattered in the compact bone of growing Rhesus monkeys.

Non-lamellar (woven) bone, in the form of fine cancellous tissue, was found to comprise the greater part of the cortical shaft in the new-born rat and monkey long bones studied (figs. 18, 24). With subsequent bone growth, both in length and diameter, these original pre-natal and neonatal deposits receive lamellar compaction (fig. 25). Following outward, inward, then outward growth, this bone becomes enclosed by more recently formed layers of other tissue types and then occupies an identifiable zone within the compacta (fig. 19B).

Non-lamellar bone may also form after birth, either in local, restricted areas or over a widespread distribution. This tissue has been routinely observed in regions of tendon insertion and in tubercle formation (fig. 20). Non-lamellar bone which is formed after birth has been found to develop, unlike coarse cancellous bone, largely by sub-periosteal rather than by endosteal deposition. The generalization may therefore be stated that cortical zones of compacted fine-cancellous, non-lamellar bone are generally a product of periosteal growth, and that compacted coarse cancellous and endochondral bone are both products of endosteal growth.

\section{Outer and inner circumferential lamellae}

If sub-periosteal apposition takes place in any area which does not involve the compaction of fine cancellous, non-lamellar bone, and if endosteal deposition does not involve compaction of endochondral or coarse cancellous trabeculae, then the formation of new bone proceeds by the deposition of uninterrupted sheets of circumferential lamellar bone tissue (figs. 14, 19, $22,23,27$ ). 
The inclusion of vascular canals in endosteal lamellar bone is in the form of "Volkmann's canals" which typically enter the compacta in a near perpendicular manner (figs. 13, 14). This pattern of Volkmann's canals is characteristically associated with endosteal circumferential lamellar bone in locations which did not involve cancellous compaction. The inclusion of primary canals during periosteal bone deposition, on the other hand, usually results in an orientation of canals which are predominantly longitudinal to the main axis of the bone, or in the form of an irregular, three-dimensional reticulum (fig. 22).

Periosteal bone is deposited along the shaft, following outward reversal in direction of growth, in a "basin" produced by the enlarging epiphyses (fig. 5). This serves to increase the diameter of the shaft, in proportion, as the whole bone enlarges. The periosteal-endosteal contact may be in the form of a simple reversal line, or it may be composed of a narrow zone of endosteal tissue composed of compacted cancellous bone (fig. 14).

Regional changes in shape and osseous drift. If cross-sections at various points in the metaphysis and diaphysis are superimposed and compared (fig. 7), it is evident that in addition to an abrupt change in size, regional shape differs significantly.

Transverse growth rarely proceeds equally in all directions, either periosteally or endosteally. Rather, one side of a bone shows external addition, and the other side of the same bone at the same level shows external resorption (Tomelin, '53). The effect is a distinct drift or shift in the local axis of bone. This lateral drift during metaphyseal-diaphyseal transition is a direct result, not only of changing size, but primarily of changing shape and change of relative position due to the formation of curvature in the bone. The arrangement of structural components in figure 12 illustrates the process. Such a pattern, or some variation of this pattern, has been routinely observed in transverse sections of bone from all species examined and at all levels from proximal to distal epiphyses.

The direction of the drift in figure 12 is clearly evident. Periosteal deposition and endosteal resorption can be identified on one side, and the converse process is found on the other side. A similar arrangement is seen in figure 27. During lateral shift in relative position, such remodeling adjustments do not affect the proportional thickness of the cortex itself. Following drift, remaining contours of the old bone are still recognizable as landmarks in the newly reorganized compacta (fig. 19). A reversal in the direction of drift may take place along the shaft as the arc of the curvature is followed.

It is proposed that this process be termed "osseous drift." Such a name is descriptive, and the process is comparable with "mesial drift" in maxillary and mandibular bone relative to movements of teeth (Orban, '57).

\section{Chondroid bone}

This distinctive tissue (fig. 20) has been observed at the crest of tubercles and bony processes in rapidly growing bones. It appears similar to or identical with the characteristic tissue located on growing alveolar crests surrounding teeth. Chondroid bone has been described (Schaffer, 1888; Orban, '57), but its developmental and functional significance is not clear. It is apparently not related to fibrocartilage, which may also be located in similar places on long bones. Rather, this curious tissue is associated with localized regions which seem to require accelerated growth and yet which must provide anchorage and perhaps resistance to pressure. Although the fibrous matrix of bone tissue in the tubercle is subject to tensile forces, the individual chondroid cells themselves do not receive direct tensile stress. To the contrary, they must be resistant to the pressure exerted on them by the surrounding fibrous matrix which is under direct tension. The cartilage-like cells appear to undergo direct conversion into osteocytes and become included in seemingly typical non-lamellar bone, although this supposition is not certain. Investigation into the nature of this tissue is urged.

Primary and secondary Haversian bone. The primary osteone is a result of concentric lamellar deposition within the spaces of fine cancellous, usually non-lamellar, bone. Secondary resorption and reconstruction are not involved. This bone type may be found following extended or local- 
ized rapid accumulation of new periosteal bone. During fast diametrical growth just following birth, stratified layers of primary osteones, together with interstitial nonlamellar tissue, are formed (figs. 24, 25). Following later remodeling, incomplete zones of this tissue remain in the compacta (fig. 19). In addition, this type of bone tissue is often present in processes to which tendons attach (fig. 20), or in any former areas of such attachment which have since been relocated through remodeling shifts. Primary osteones located selectively in tubercles seem to result from the formation of original fine cancellous deposits resulting from disproportionately rapid growth in this area. They are apparently not implicated, in a direct cause and effect relationship, with stress forces associated with muscle or tendon insertion. This observation is in contradiction to the hypothesis that "osteones" represent a response to tension (Murray, '36).

Internal reconstruction within the compacta itself results in the formation of bone tissues which are composed largely of secondary osteones. Secondary Haversian bone is not involved in the bone tissue of many mammalian species, including the white rat (Enlow and Brown, '58).

Primary and secondary osteones, like any other bone tissue type, occur regularly in distinct zones within the compacta. The sequential, developmental history of these zones can be traced and interpreted on the basis of preceding descriptions. Primary osteones are found in growing bone of both the rat and monkey, but distribution is noticeably sparse in the rat. This can be explained on the basis of comparative differential growth and the relative quantities of bone which are deposited in a given period, since the primary osteone is a structural result of larger volumes of bone formation in less time.

Structural variations in different bones. The relative proliferative activity of the proximal and distal epiphyseal cartilages is an important factor contributing to architectural arrangement within the cortex of the shaft. Inequalities in growth rate produce a characteristic distribution of endosteal and periosteal bone tissues which is identified with specific bones. The proximal and distal epiphyseal plates of the tibia are approximately equal in their contribution to the overall length of the whole bone. Periosteal deposition in the tibia, as evidenced by alizarin lines or by the identification of zones and associated tissues, occupies a considerable area extending well toward both epiphyses. In the femur (fig. 8), however, the proximal epiphyseal plates are subordinate to the growth activity of the distal plate, and they provide linear growth which is restricted largely to the neck and to the greater or lesser trochanters. As a result, bone formed by endosteal apposition following proliferation of the distal plate represents the predominant cortical volume in the growing shaft (fig. 9).

The diameter of the femoral neck, following the proliferation of its own epiphyseal plate, becomes reduced by periosteal resorption together with endosteal compaction of underlying cancellous bone (fig. 8). Sub-periosteal lamellar apposition appears as the neck grades into the adjacent shaft. The contact zone between this endosteal bone and the periosteal bone of the shaft is evident in microscopic sections.

\section{DISCUSSION}

The traditional textbook pattern of compact bone tissue structure is a combination of outer and inner circumferential lamellae enclosing a middle core of Haversian bone (fig. 23). This is one example of the multi-layering of zones produced by inward and outward reversals in growth. Such an arrangement is rarely so simple, however. If the formation and structural arrangement of compact bone is considered with respect to the various remodeling agencies, including metaphyseal-diaphyseal transition, changes in shape, zone formation, shifts in axis, osseous drift, the formation and reformation of bony processes, and the development of various bone tissue types, it is apparent that a considerable variety of structural patterns are likely to be encountered. A mid-diaphyseal, transverse section will differ from one prepared near the end of the diaphysis, and this in turn differs noticably in structural arrangement from sections made through the metaphysis, and so on up and down levels of the bone (plate 7). Correspondingly, the various sections differ with age, 
with the specific skeletal unit studied, and with the particular species considered.

If a transverse section is prepared through the approximate level of $7 \mathrm{~b}$ in figure 6 , three or 4 clearly identifiable zones would be expected. These actual zones are observed in figure 19 , a cross section through such an area. The original endochondral trabeculae of the metaphyseal medulla, containing spicules of calcified cartilage matrix, can be identified. These trabeculae have been compacted and subsequently were incorporated as a zone within the cortex during inward growth. External to this layer, sub-periosteal, fine cancellous, non-lamellar bone has been filled with lamellae to form another distinct zone. The results of inward growth by endosteal lamellar apposition, and outward growth by periosteal lamellar deposition following reversal, can both be recognized as inner and outer circumferential zones or layers. The results of drift, following a shift in axis, are seen as the zones arch to the periosteal margin (fig. 19) and there become exposed as an active surface of erosion. The middle two zones in figure 19 appear abruptly sheared at the outer cortical margin. Periosteal and endosteal lamellar deposition have followed in the direction of the shift.

In view of the various factors just described, it is evident that any section of bone must be interpreted as an individual and local situation which has been produced by the cumulative effects of gross remodeling in that particular region.

Species variation. Widespread differences exist in the structure of bone between vertebrate groups (Foote, '16; Petersen, '30; Amprino and Godina, '47; Enlow and Brown, '56, '57, '58). The basis for many of these structural differences can be resolved by a comparative interpretation of developmental processes. The results of this study suggest that differential rates of growth between different species is an important factor. This was first proposed and supported by Amprino ('47). The rate of deposition determines the volume of bone laid down in a given period of time, and this strongly influences the particular type of bone tissue which is to be deposited. The widespread distribution in a skeleton of fine cancellous non-lamellar bone, primary Haversian bone, or plexiform bone
(Enlow and Brown, '56), represents a developmental response to relatively rapid skeletal growth, or to the production of large quantities of bone tissue in a short period of time, as in bovines, larger carnivores, and proboscidians. Relatively slow skeletal growth, on the other hand, results in the formation of typical circumferential lamellar bone, either with or without the inclusion of primary non-Haversian canals. Certain vertebrate groups, including most reptiles, have this particular bone variety as a predominant and characteristic component of structure. A great many forms possess bone types which are associated with more rapid accretion, but subsequent to periods of active skeletal growth, other bone tissue varieties characteristic of slower growth are produced. This may be either a local or a widespread situation in any individual bone. Mixed combinations of bone tissue types, thus, are frequently present. Related to differential rate of growth is the life span of the form, and the size, specific shape, and the proportions of individual bones considered. These factors determine the regional distribution of various tissue types and represent individual structural results produced by remodeling processes. Marked differences are found, for example, in the bone structure between the laboratory rat and human or monkey bones. This can be explained on the basis of the endosteal and periosteal distribution of bone which determines the nature and orientation of component structures, and which is in direct relation to differences in growth rate and size of the forms. Small rodents, as well as other mammals of similar size and with a similar rate of skeletal growth, possess middiaphyseal bone which has a predictable "radial" orientation of vascular canals in the compacta (Enlow and Brown, '58). Since much of the cortex in the mid-diaphysis of a rat long bone is composed of endosteal, circumferential lamellar bone (fig. 9 ), the radial arrangement of Volkmann canals is explicable (see previous descriptions of endosteal lamellar bone). In mammalian forms of larger body size, however, the progressively increased diameter of the diaphyseal cortex, following reversals of growth, results in the addition of relatively greater amounts of periosteal bone with a proportionate removal of endosteal bone. 
The distribution of endosteal, radial canals, while present, is thus minimal except in local areas where the diameter of the shaft is undergoing active reduction during gross remodeling.

\section{Generalized sequence of growth}

Based on the structural observations previously described and discussed, the traditional plan of superimposed growth stages (figs. 1, 2, 3) has been expanded (figs. 4, $5,6)$. The purpose of this more detailed scheme is to illustrate the developmental sequence in (a) the regional formation of cortical zones, (b) the formation and arrangement of different tissue types, and (c) the progressive rearrangement and relocation of structural components during remodeling processes.

Stage one (fig. 4). Specific areas and zones are identified by code numbers.

Alizarin deposits are scattered beneath the epiphyseal plate from $10 \mathrm{a}$ to $11 \mathrm{a}$ and from $10 \mathrm{~b}$ to $11 \mathrm{~b}$ as linear growth proceeds by endochondral ossification. Metaphyseal diameter has increased from $9 \mathrm{~b}$ to $11 \mathrm{~b}$ by the sub-periosteal apposition of fine cancellous, non-lamellar bone tissue forming an intramembranous sheath of bone around the endochondral medulla (fig. 15). Note that the diameter of the metaphysis in this same region on opposite side (10a to 11a) has undergone reduction. A sheath of subperiosteal bone is not present, and the endochondral trabeculae have been abruptly and directly invaded by inward resorption (fig. 16). This arrangement in an actual bone section is seen in figure 11. Metaphyseal reduction in diameter by periosteal resorption has also occurred from 3a to $11 \mathrm{a}$ and from $3 b$ to $9 \mathrm{~b}$. Compaction of coarse cancellous bone during inward growth is seen from $6 a$ to $11 \mathrm{a}$ and from $6 \mathrm{~b}$ to $9 \mathrm{~b}$. With continued elongation of the entire bone, following epiphyseal activity, this area will become partially interred between more recently formed endosteal and periosteal layers produced by subsequent inward and outward reversals (see Stages two and three). Endosteal deposition of internal circumferential lamellae during metaphyseal reduction is seen from $3 a$ to $6 a$ and from $2 \mathrm{~b}$ to $6 \mathrm{~b}$. Cancellous compaction is not involved in these areas. The diameter of the mid-diaphysis has increased by subperiosteal growth from $1 \mathrm{la}$ to $3 \mathrm{a}$ and from
$1 \mathrm{~b}$ to $2 \mathrm{~b}$ following outward reversal in direction of growth. This periosteal bone tissue may be in the form of circumferential lamellae (figs. 22, 23) or fine cancellous non-lamellar bone (fig. 24) depending on relative rates of growth. Deposits of fine cancellous bone, when formed, received subsequent lamellar compaction.

Stage two (fig. 5). Cancellous bone in the metaphysis has been omitted for clarity of illustration, but the arrangement in this region would be a repetition of Stage one. Areas of bone remaining from Stage one (solid black) are embedded within the new bone of this generation, and the distribution of alizarin lines partially describe the contours of the old bone.

Increase in diameter by sub-periosteal deposition of fine cancellous, non-lamellar bone has occurred from $14 \mathrm{~b}$ to the end of the metaphysis. Periosteal resorption during metaphyseal reduction, following inward reversal in direction of growth, can be seen from $4 b$ to $13 b$ and $6 a$ to $15 a$. Compact bone produced by cancellous compaction during endosteal growth is present from $7 \mathrm{a}$ to $11 \mathrm{a}$ and from $6 \mathrm{~b}$ to $11 \mathrm{~b}$. Irregular contours of old alizarin lines are seen. This zone represents levels $6 \mathrm{a}$ to $10 \mathrm{a}$ and $6 \mathrm{~b}$ to $10 \mathrm{~b}$ in Stage one following compaction and relocation. Endosteal deposition of circumferential lamellae during reduction in diameter has occurred from $5 \mathrm{a}$ to $7 \mathrm{a}$ and from $3 \mathrm{~b}$ to $7 \mathrm{~b}$, and endosteal growth by the compaction of cancellous trabeculae has proceeded from 11 a to $15 \mathrm{a}$ and from $11 \mathrm{~b}$ to $14 \mathrm{~b}$. Increase in diameter by the sub-periosteal apposition of either circumferential lamellar or fine cancellous non-lamellar bone is seen from $1 \mathrm{a}$ to $6 \mathrm{a}$ and from $1 \mathrm{~b}$ to $4 \mathrm{~b}$. The eroded surfaces of Stage one are present on the outer margin of the bone from $6 a$ to $11 \mathrm{a}$ and from $4 \mathrm{~b}$ to $11 \mathrm{~b}$. In this region, the external surfaces are composed of older bone which was originally endosteal in its formation and which was located on the inner surface. This bone tissue has been relocated from the inner to the outer side where it now occupies a resorptive surface during metaphyseal reduction in diameter.

Stage three (fig. 6). The old contours of Stage one (black) and Stage two (lined) can be observed within the present growth stage (stippled). Deeply enclosed alizarin lines formed during Stage one are still ap- 
parent. Note that the contours of the bone as a whole are maintained as symmetrical, even surfaces although the substance of the compact bone itself is a composite of irregular zones. Periosteal resorption has taken place from $7 \mathrm{~b}$ to $18 \mathrm{~b}$ and from $7 \mathrm{a}$ to 20 a. Endosteal deposition by cancellous compaction (in the metaphysis), or by the apposition of inner circumferential lamellae (toward the diaphysis), has proceeded from $5 \mathrm{a}$ to $20 \mathrm{a}$ and from $4 \mathrm{~b}$ to $18 \mathrm{~b}$. Earlier zones of compacted cancellous bone from $7 \mathrm{a}$ to $12 \mathrm{a}$ and from $6 \mathrm{~b}$ to $10 \mathrm{~b}$ are now partially or completely enclosed by subsequently formed zones of other tissue types produced during growth reversals. Outward, sub-periosteal deposition has taken place from $1 \mathrm{a}$ to $7 \mathrm{a}$ and from $1 \mathrm{~b}$ to $7 \mathrm{~b}$. The inner surface of the mid-diaphysis now undergoes resorption (not shown in diagram) as the diameter of the shaft increases.

\section{SUMMARY AND CONCLUSIONS}

The cortex is composed of stratified compact bone. Each stratum represents a distinct growth "zone," and the composite of zones represents the cumulative result of various remodeling processes outlined below.

Repeated endosteal and periosteal reversals in direction of lateral growth contribute to the formation and stratification of cortical zones. Growth reversals follow the increase-decrease-increase of diameter involved in metaphyseal to diaphyseal relocation of compact bone during linear growth.

Regional, progressive changes in sectional shape involved in metaphysealdiaphyseal relocation are produced by a process termed "osseous drift."

Zone formation involves a variety of basic osseous tissues. Specific bone tissue types are characteristically associated with particular zones.

Fine cancellous, non-lamellar bone tissue is widely distributed in the neo-natal cortex. In post-natal long bones, this bone type has been observed to develop largely by sub-periosteal rather than by sub-endosteal apposition. Compacted fine cancellous bone occupies distinct zones in the cortex following the formation of other zones and tissue types during subsequent growth reversals.
Since the contour of existing bone surfaces at any stage of developmental reorganization determines the architecture and configuration of subsquent bone deposits, inward growth by endosteal deposition produces several distinctive bone tissue varieties. Cortical bone resulting from the lamellar compaction of fine cancellous endochondral trabeculae is identifiable by the presence of calcified cartilage spicules. Endosteal growth into areas occupied by coarse cancellous trabeculae produces "whorls" of irregular, compacted cancellous bone. This is a common tissue type in the proximal and distal thirds of the shaft. Inward endosteal growth uncomplicated by the presence of cancellous bone results in the formation of inner circumferential lamellae. These various tissue types are routinely seen as distinct zones in the compacta following growth reversals. Different tissue types represent a response not only to local direction of growth, but also to differential rate of local growth.

Marked variation exists in the structure of bone between different ages, different bones, and between different sections at various levels of the same bone. These structural variations can be explained on the basis of regional developmental and remodeling processes.

Species variations in the microscopic structure of bone can be largely explained by a comparative interpretation of the specific growth processes described in this study.

\section{ACKNOWLEDGMENTS}

The author is indebted to Miss Harriet Jameson, Rare Book Librarian at the University of Michigan, for her assistance in the translation of difficult passages from early Latin works.

Large numbers of healthy, normal, embalmed specimens of young, growing monkeys were made available through the courtesy of Dr. Paul Ayres, Parke Davis and Co., Rochester, Michigan. Rare bone materials from older monkeys of known age were provided by Dr. G. van Wagenen, Department of Obstetrics and Gynecology, Yale University. Bones from neo-natal Rhesus monkeys were provided by Dr. William F. Windle, Director, National Institute of Neurological Diseases and Blindness, National Institute of Health. Numerous bone specimens were made available by 
Dr. James Gavin, Medical College of South Carolina. Rats were provided by the Upjohn Co.

\section{LITERATURE CITED}

Albinus, B. S. 1757 Accademicorum annatatonum. $7: 48-49$.

Amprino, R. 1947 La structure du tissue osseux envisagee comme expression de differences dans la vitesse de l'acroissement. Arch. de Biol. LVIII, 4: 315-330.

Amprino, R., and A. Bairati 1936 Processi di ricostruzione e di riassorbiments nella sostanza compatta della ossa dell'umo. Zschr. Zellfarsch., 24: 439-511.

Amprino, R., and G. Godina 1947 La struttura delle ossa nei vertebrati. Comment. Pont. Acad. Sci., 11: 329-467.

Bartholin, C. 1676 Diaphragmatis structure nova. Acta med. et thil., Hafn., 4: 14-16.

Belchier, J. 1736 An account of the bones of animals being changed to a red colour by aliment only. Phil. Trans., 34: 287-299.

Brash, J. C. 1934 Some problems in the growth and developmental mechanics of bone. Edinb. Med. J., 41: 305-318, 363-387.

Brulle and Hugueny 1845 Experiences sur le developpement des os mammiferes et les oisseaux. Ann. des Sci. Nat., IV: 283-357.

Cheselden, W. 1733 Osteographia. London.

Duhamel, H. L. 1739 Sur une racine qui a la faculte de teindre en rouge les os des aninauz vivants. Mem. Aca. R. Sci. Paris, 1-13.

_- 1742 Sur le developpement et la crue des os des animaux. Mem. de l'Acad. Roy. des Sci.

Ibid.

1743 Cinquieme memoire sur les os.

Enlow, D. H. 1954 A plastic-seal method for mounting sections of ground bone. Stain Tech., 29: 21-22.

1961 Preparation of decalcified and stained sections of bone by thin-section grinding. Ibid., July, 36, 4: 250-251.

1961 Sequence of microscopic structural changes involved in the gross remodeling of bone. Abstract, Anat. Rec., 139: 226.

Enlow, D. H., and S. O. Brown 1956 A comparative histological study of fossil and recent bone tissues. Part I, Tex. J, Sci., VII, No. 4: $405-443$.

- 1957 A comparative histological study of fossil and recent bone tissues. Part II, Ibid., IX, No. 2: 186-214.

IX, 1958 A comparative histological study of fossil and recent bone tissues. Part III, Ibid., $\mathrm{X}$, No. 2: 187-230.

Flourens, M. 1845 Experiences sur la resorption et la reproduction successives des tetes des os. Ann. d. Sci. Nat., IV: 358-363.

Foote, J. S. 1916 A contribution to the com parative histology of the femur. Smithsonian Contr., XXXV: 3.

Frost, H. M. 1960 Observations on fibrous and lamellar bone. Henry Ford Hosp. Med. Bull. 8: 199-207.

Grew, N. 1681 Natural and artificial rarities. London, 6.

Hales, S. 1727 Vegetable statics.
Haller, A. V. 1766 Elementa physiologiae corporis humani.

Havers, C. 1691 Osteologia nova. London.

Hoyte, D. A. N. 1960 Alizarin as an indicator of bone growth. J. of Anat., 94: 432-440.

Hunter, J, 1798 Experiments and observations on the growth of bones. Hunter's works: PaImer's Ed. 1837, p. 315.

Huxley, T. 1853 Edited translation of Manual of Human Histology, by A. Kolliker.

Kölliker, A. 1853 Manual of human histology. Trans. by George Bush and Thomas Huxley, London, 1: 365.

Lacroix, P. 1945 Remarques sur le mecanisme de l'allongement des os. Arch. de Biol., 56: 185-197.

Leblond, C. P., G. W. Wilkinson, L. F. Belanger and J. Robichon 1950 Radio-autographic visualization of bone formation in the rat. Am. J. Anat., 86: 289-341.

Leeuwenhoek, A. 1693 Observations on the texture of the bones of animals compared with that of wood. Phil. Trans. Roy. Soc. London, 17: $561-562$.

Lemnius 1567 De miraculis occultis naturae. Colonia.

Loven, C. 1863 Studier och undersökningar öfver Benväfnaden, förnämligast med afseende pa dess utueckling. Stockholm.

Malpighi, M. 1743 De ossium structura. Ex. Op. Posth., Venice.

Meckel, J. F. 1832 Manual of anatomy. Translated by Jourdan and Breschet. Philadelphia, 1: 209.

Mizaldus 1566 Memorabilium utilium et jucundorum centurie. Lutetiae.

Monro, A. 1763 The anatomy of the human bones. Edinburgh.

Murray, P. D. F. 1936 Bones. Cambridge University Press. P. 167-171.

Nesbitt, R. 1736 Human osteogeny. London.

Orban, B. J. 1957 Oral histology and embryology. C. V. Mosby Co., p. 208-216.

Payton, C. G. 1931 The growth in length of the long bones in the madder-fed pig. J. Anat. 66: 414-425.

Petersen, H. 1930 Die Organe des Skeletsystems. Handbuch der Mikroskopischen Anatomie des Menschen. V. Moellendorf, Berlin, p. 521679.

Portal, A. 1770 Historie de l'anatomie et de la chirurgie. Paris. P. F. Didot le June. 53.

Pritchard, J. J. 1956 General anatomy and histology of bone. Biochemistry and Physiology of Bone, ed. by G. H. Bourne, Acad. Press., N. Y., p. 1-25.

Schaffer, Josef 1888 Die Verknocherung des Unterkiefers und die Metaplasiefrage. Arch. Mik. Anat., 32: 300.

Spigelius, A. 1631 De formato foetu. Opus posthumum, p. 61.

Smith, J. W. 1961 Collagen fibre patterns in mammalian bone. J. of Anat., 94: 329-344.

Tomelin, D. H., K. M. Henry and S. K. Kon 1953 Autoradiographic study of growth and calcium metabolism in the long bones of the rat. Brit. J. Nutrit., 7: 235-251.

Weinmann, J. P., and H. Sicher 1955 Bone and bones. 2nd Ed. C. V. Mosby Co. 


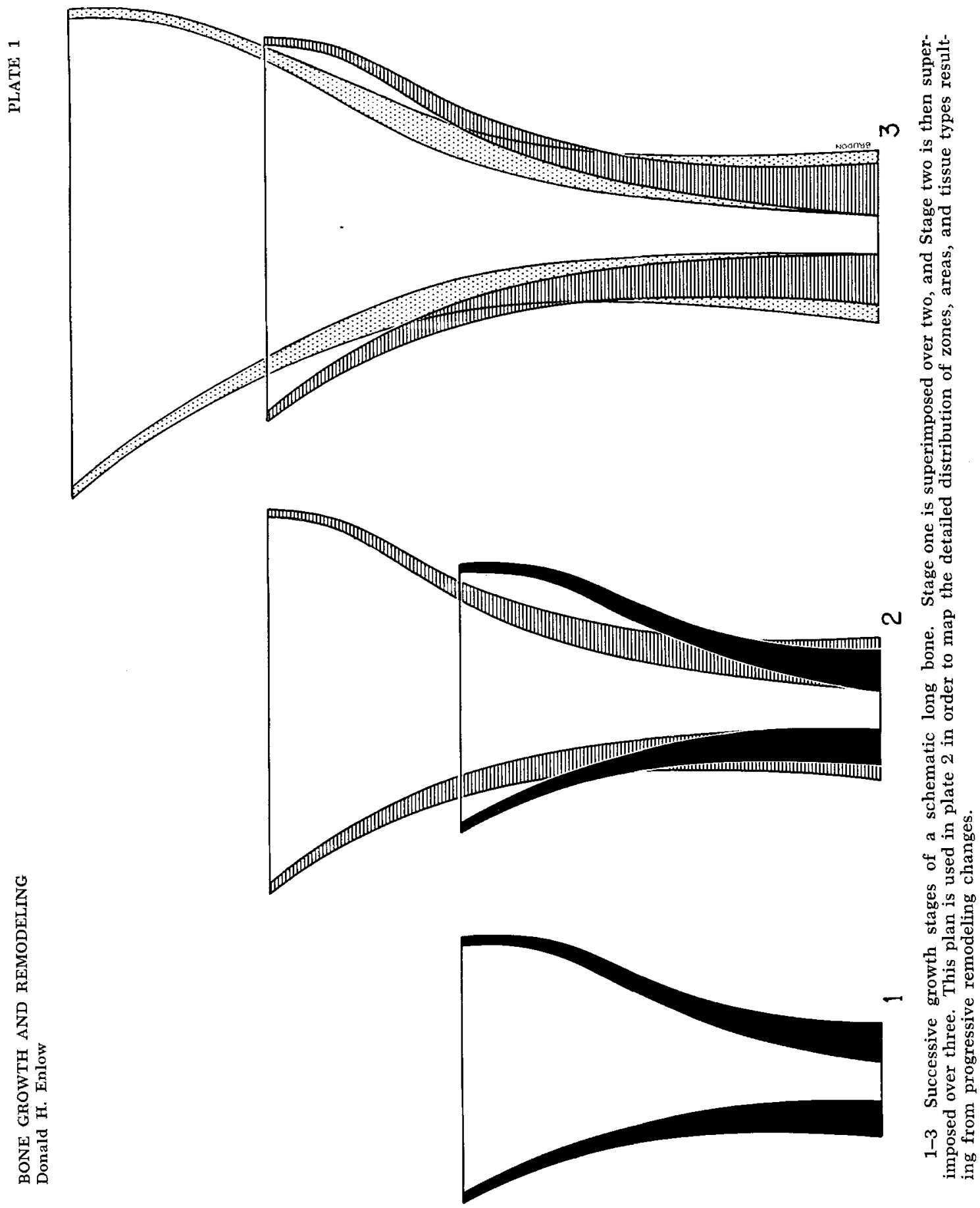




\section{PLATE 2}

EXPLANATION OF FIGURES

4 Stage One, represented in black. Remnants of this growth level, following subsequent remodeling, can be traced in figures 5 and 6 . Alizarin markers are indicated by red lines. Detailed explanation in text.

5 Stage Two, represented by a horizontal-lined pattern. Metaphyseal cancellous bone, as found in Stage one, is omitted for simplicity of illustration. The alizarin markers of Stage one have been enclosed by subsequent endosteal or periosteal deposits. Detailed explanation in text.

6 Stage Three, represented by a stippled-pattern. Endosteal and periosteal deposition has enclosed vestiges of Stages two and three following remodeling. Detailed explanation in text. 

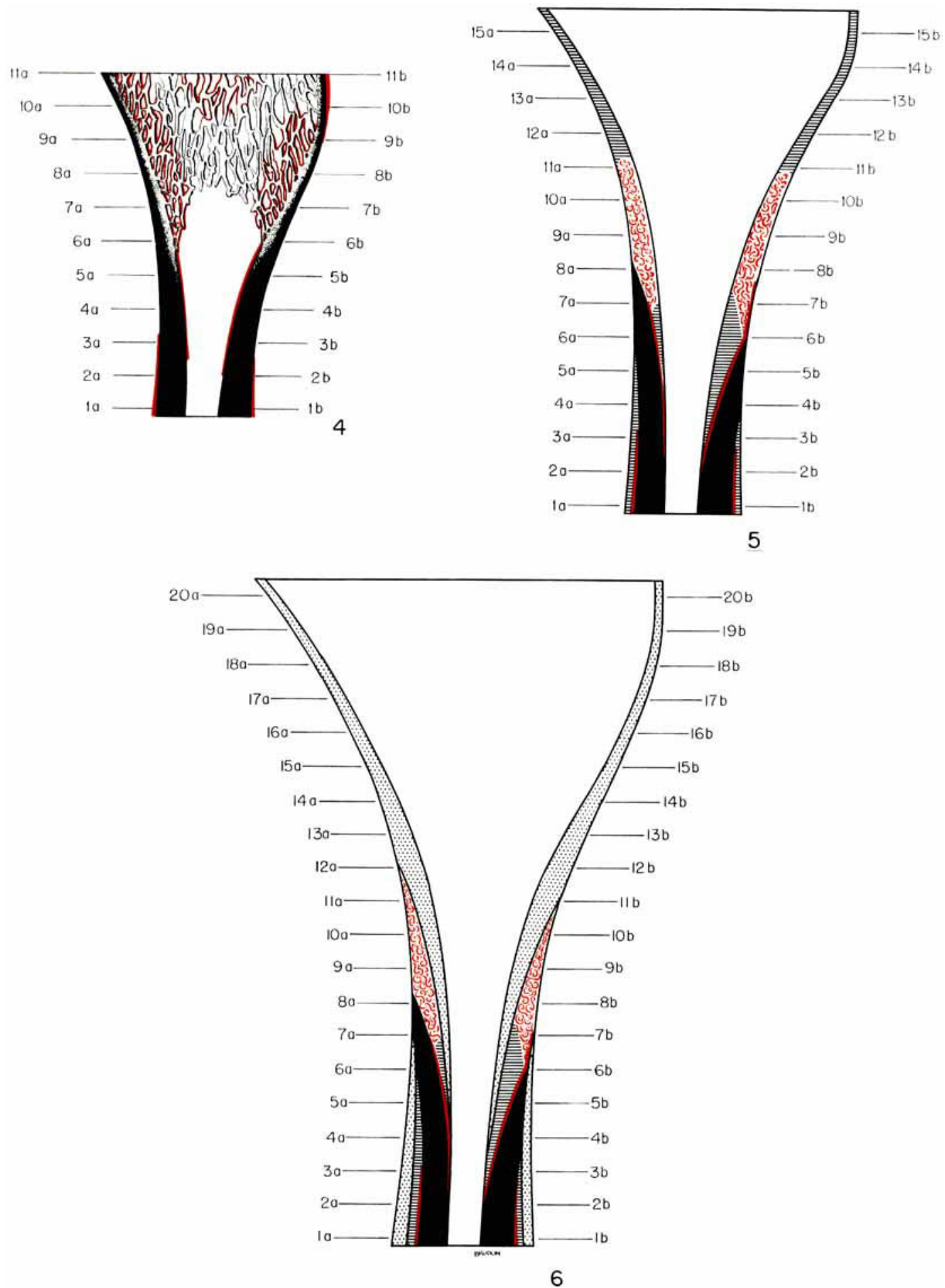
PLATE 3

EXPLANATION OF FIGURES

7 A lateral shift in axis during metaphyseal-diaphyseal transition is involved in changes of shape and size, as well as in the curvature formation of the bone. This process is termed "osseous drift." The structural results of lateral drift, as level A is superimposed over level B, can be seen in figure 12.

8 Longitudinal section of a growing post-natal rat femur. Alizarin markers are indicated by black lines. Cancellous compaction, recognizable by the convoluted nature of the tissue, can be seen in the distal metaphysis and in the neck. Extensive endosteal growth, as indicated by alizarin markers, has formed in the distal half of the bone. Subperiosteal deposition has occurred in the proximal "basin" of the shaft adjacent to the neck.

9 Periosteal bone is represented by solid black, and endosteal bone is white. Note the widespread distribution, in the growing rat femur, of endosteal bone. Enlargements of areas $X$ and $Y$ are found in plate 4, figures 13 and 14 . 

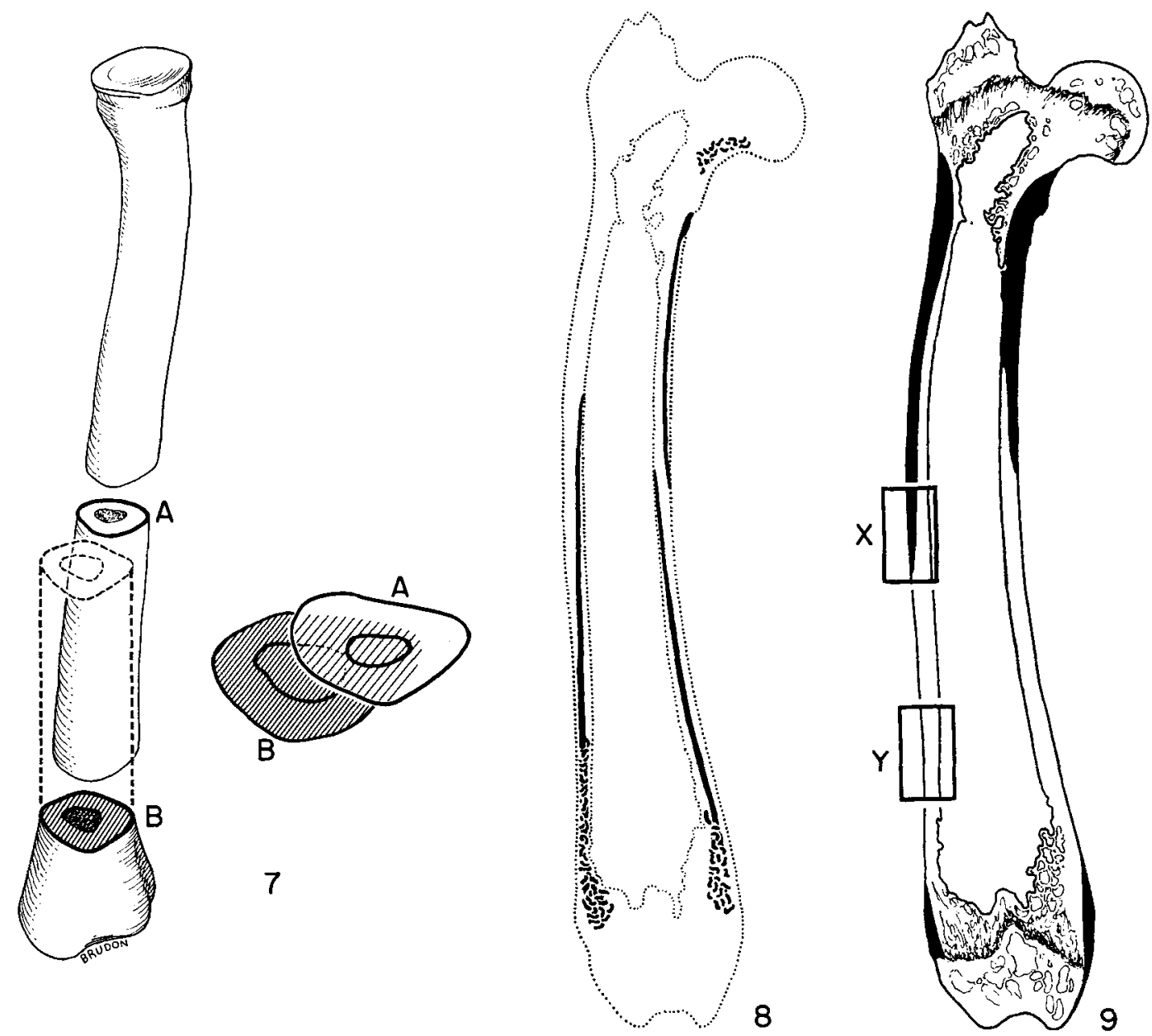


\section{PLATE 4}

\section{EXPLANATION OF FIGURES}

10 Longitudinal section of a growing rat femur. $\times 3$. The information presented in figures 8 and 9 , and the enlargements in figures 13 and 14 , were made from this section.

11 Longitudinal section of a growing rat tibia. $\times 1.5$. Compare opposite sides of the proximal metaphysis. One side (B) shows sub-periosteal apposition adjacent to the epiphyseal plate, while the other side (A) has received immediate reduction by a process of periosteal resorption in combination with endosteal deposition. See figures 15 and 16 below for comparable sections under higher magnification.

12 This transverse section of a growing monkey humerus illustrates the structural result of osseous drift. Periosteal lamellar apposition (A) is combined with endosteal resorption (B) on one of the sections, and endosteal lamellar apposition (C) and periosteal resorption (D) is seen on the opposite side. Drift has proceeded in a direction toward the top of the illustration. This common situation is found in routine bone sections of all species and at all age levels. $\times 6$.

13 Enlarged transverse section of Area $Y$, figure 9. $\times 50$. This area of compact bone is composed entirely of endosteal bone tissue. Growth has proceeded from left to right by a process of endosteal apposition and periosteal resorption. The metaphysis is undergoing reduction in diameter. Note the characteristic perpendicular arrangement of canals in this endosteal bone. Compare this pattern with the periosteal canals seen in figure 22.

14 Enlarged transverse section of Area $X$, figure $9 . \times 50$. The arrow indicates the contact between endosteal bone, toward the right, and periosteal bone, on the left. The middle zone is composed of endosteal bone which was formerly located in the metaphysis. Three zones are thus seen, representing the structural product of growth reversals involved in metaphyseal to diaphyseal remodeling.

15 Longitudinal section of a developing human long bone adjacent to the epiphyseal plate. $\times 30$. Note the increase in diameter by sub-periosteal apposition of non-lamellar bone in the area indicated by the arrow. Compare with level $10 \mathrm{~b}$, figure 4.

16 This is the opposite side of the same section seen in figure 15 . $\times 30$. Here the diameter of the bone is undergoing reduction (arrow) by the periosteal invasion of recently formed endochondral trabeculae. Note the total absence of sub-periosteal bone. Compare with area 10a, figure 4. Although the epiphysis and immediately adjacent metaphyseal areas are increasing in diameter, the metaphysis itself is being reduced in dimension in a direction toward the diaphysis. Progressive endosteal growth will later result in cortical, compact bone which embodies remnants of older endochondral trabeculae. Such a zone following repeated growth reversals, can be seen in figure 19 

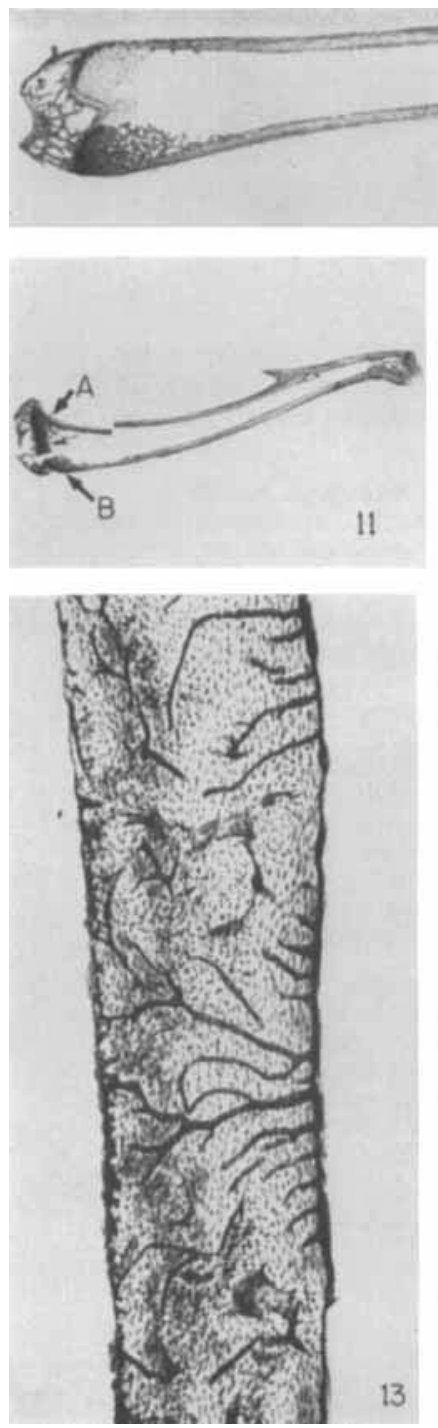
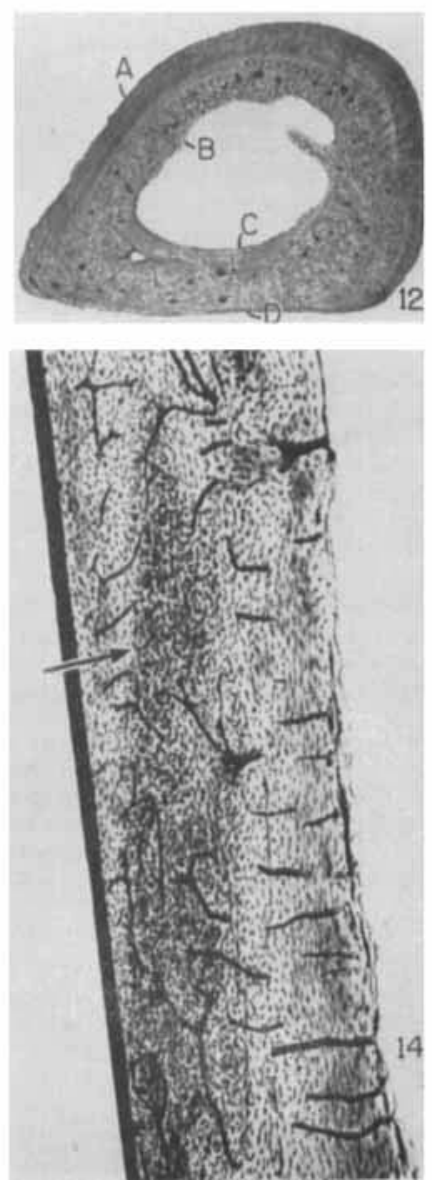
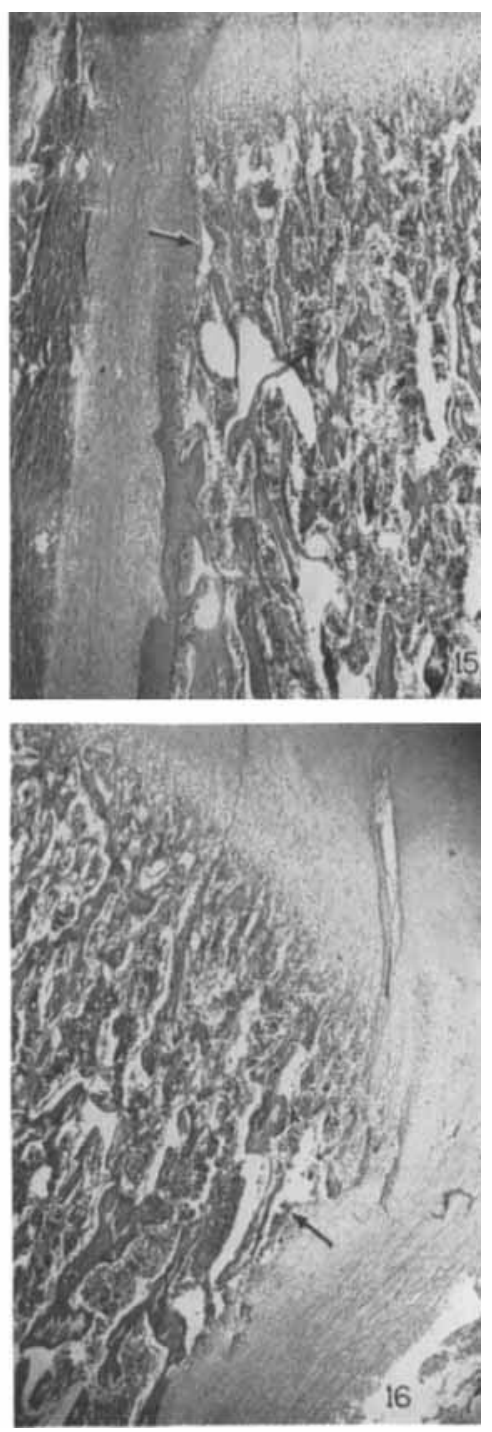
PLATE 5

EXPLANATION OF FIGURES

17 Endosteal lamellar growth in the long bone of a post-natal rodent (Cavia). $\times 100$. A cancellous trabecula (arrow) is being progressively enclosed within the cortex during inward growth. Such a pattern is frequently observed in compact bone located in or near the metaphysis.

18 Non-lamellar, fine cancellous bone in the mid-diaphysis of a neo-natal rat tibia. $\times 60$. Subsequent compaction of this bone, together with the formation of additional layers following reversals in direction of growth, will produce a stratified cortex composed of distinctive zones, as illustrated in figure 19.

19 Transverse section of a growing post-natal rat femur through a level represented by $7 \mathrm{~b}$, figure 6. $\times$ 60. Four zones are evident. Sub-periosteal lamellar deposition (A) is seen on the outer margin of the bone at the top of the illustration. Beneath this circumferential layer is a zone (B) of compacted, fine cancellous bone composed of primary osteones with non-lamellar interstitial tissue. This specific zone is a structural derivative of the bone tissue type, either neo-natal or post-natal, seen in figure 18 (above) or in figure 20. A zone of compacted endochondral bone $(C)$ is present in the mid-compacta. Vestiges of calcified cartilage spicules have been retained. This is a result of endosteal growth into an area of older metaphyseal fine-cancellous trabeculae produced by the epiphyseal plate. A layer of circumferential lamellae (D), following continued endosteal growth, is found on the inner margin. The results of osseous drift are evidenced by the eccentric orientation of the partially removed component zones.

20 Transverse, mid-diaphyseal section through the femur of a young, growing rat. $\times 50$. Observe the formation of fine-cancellous, non-lamellar bone by sub-periosteal deposition (B). Lamellar filling of the enclosed primary spaces will later produce primary osteones separated by non-lamellar, interstitial bone, as seen in figure 19, B. The characteristic occurrence of primary osteones in bony processes is a frequent observation. Note the presence of chondroid tissue (A) at the apex of the enlarging process. 

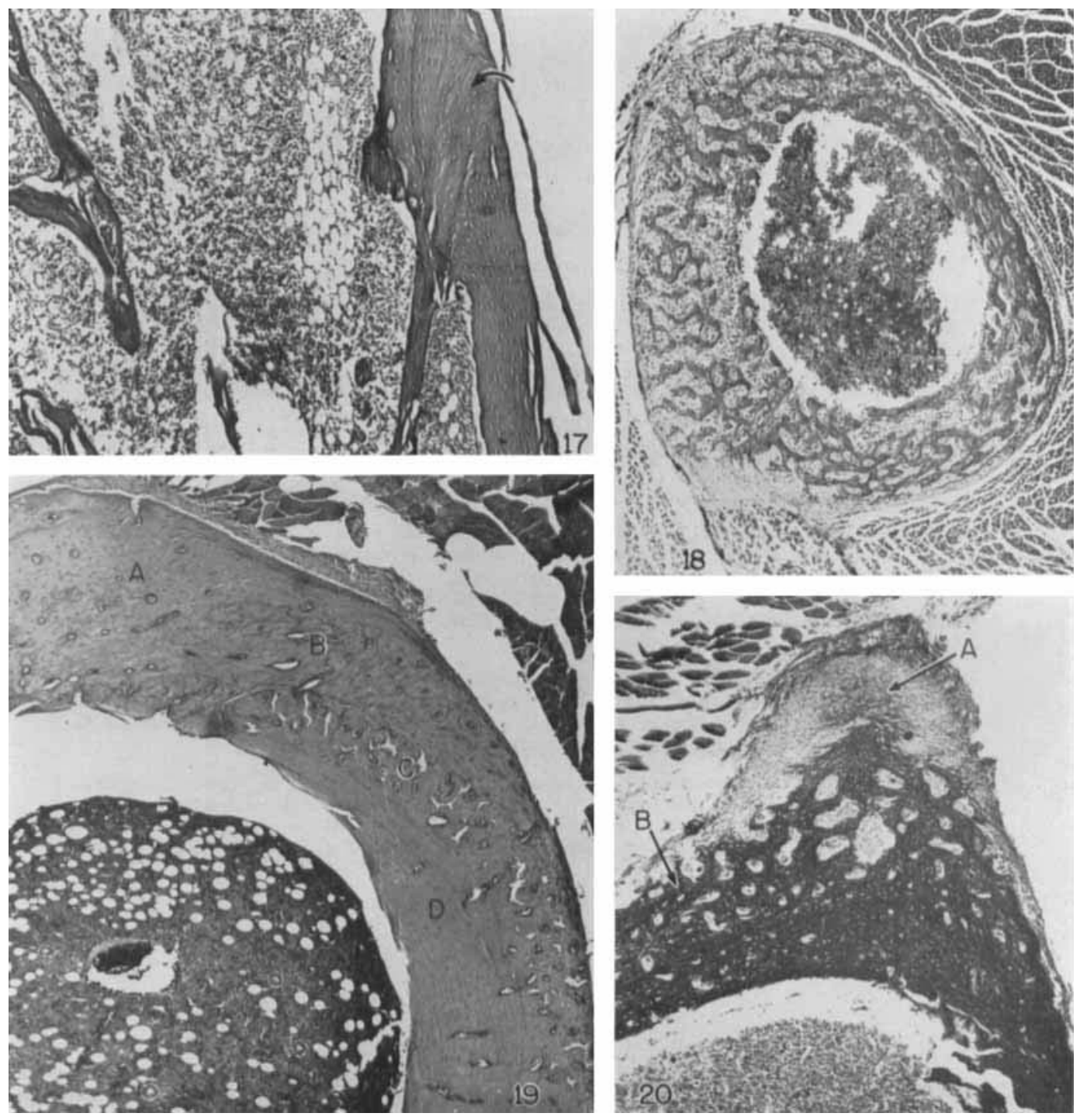


\section{PLATE 6}

\section{EXPLANATION OF FIGURES}

21 Transverse section through the femoral metaphysis of a growing Rhesus monkey. $\times 60$. "Whorls" of convoluted bone are produced by the lamellar filling of coarse-cancellous trabeculae. This characteristic pattern of bone tissue structure is common in the proxi$\mathrm{mal}$ and distal thirds of a long bone, or in any skeletal element involving inward growth (endosteal apposition together with periosteal resorption) into coarse spongy bone.

22 Transverse section through the long bone of a large rodent, (Castor). $\times 60$. Two zones may be distinguished. The compacted coarse-cancellous bone has resulted from inward endosteal growth. Following reversal, sub-periosteal deposition has produced a zone of outer circumferential lamellae.

23 Transverse, mid-diaphyseal section through the femur of a growing Rhesus monkey. $\times 50$. This is the classic picture of inner and outer circumferential lamellae enclosing a middle layer of Haversian bone. The structural arrangement is produced by inward and outward reversals in direction of growth, and this pattern is typically found in the middle third of the shaft in those species which characteristically possess Haversian systems.

24 Fine-cancellous, non-lamellar bone (arrow) deposited by sub-periosteal apposition in the femur of a neo-natal monkey. $\times 80$. Bone produced by this type of growth is extensively distributed in the fetal skeleton, and it is typically found in post-natal bone in specific, localized areas of rapid growth, as well as in early callus formation.

25 Following lamellar compaction of the bone tissue type illustrated in figure 24, primary (not secondary) osteones are formed. $\times 100$. The original fine-cancellous bone is now interstitial in location between primary osteones. Subsequent reversals in direction of growth will produce additional enclosing zones composed of different bone tissue types. 

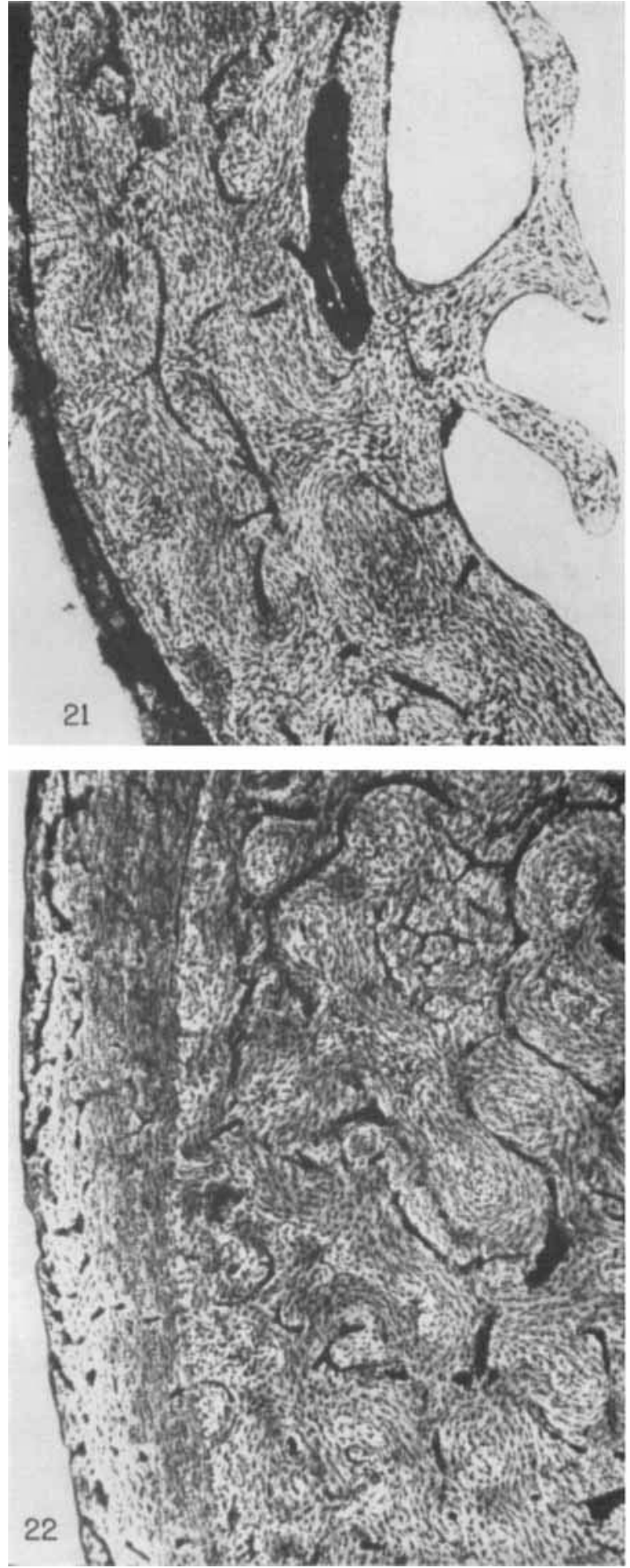
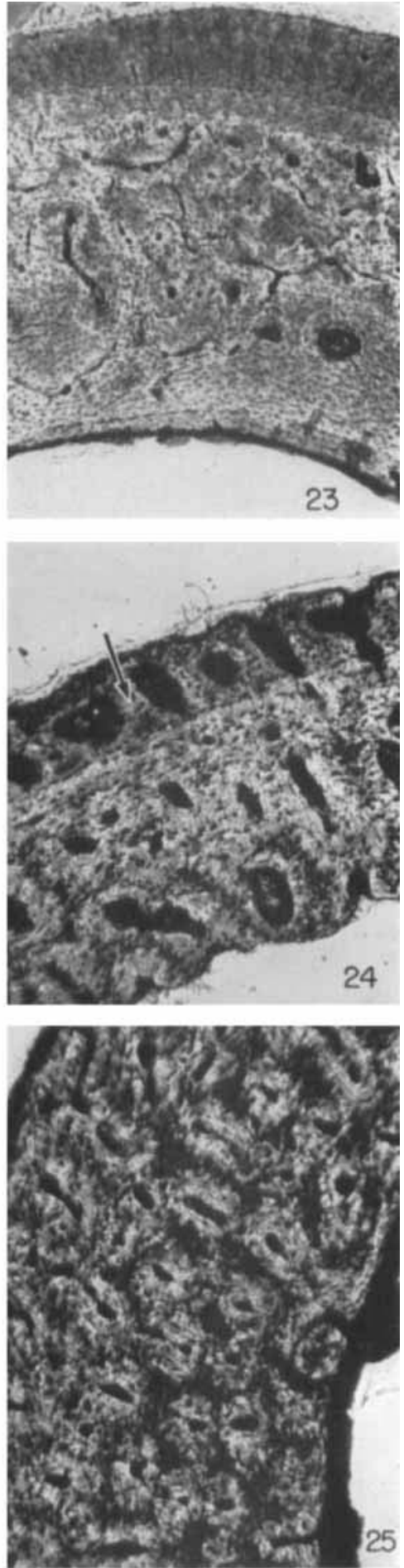


\section{PLATE 7}

EXPLANATION OF FIGURES

26 Tibia, Rhesus monkey. $\times 11.5$. The cortex is composed entirely of compacted coarse cancellous bone (B) produced by endosteal deposition during reduction in diameter.

27 A layer of circumferential lamellae produced by outward growth (A) encloses a zone of compacted coarse cancellous bone (B) produced during endosteal growth. An inner zone of endosteal circumferential lamellae (C) has formed in an area lacking cancellous trabeculae. Note that the bone has "drifted" laterally, to the right.

28 Periosteal circumferential bone (A) encloses an inner zone of endosteal bone produced by compaction of coarse cancellous trabeculae. Note the irregular orientation of canals and the "whorled" arrangement of lamellae in the endosteal bone.

29 Cortical bone composed entirely of endosteal, compacted coarse cancellous bone. 

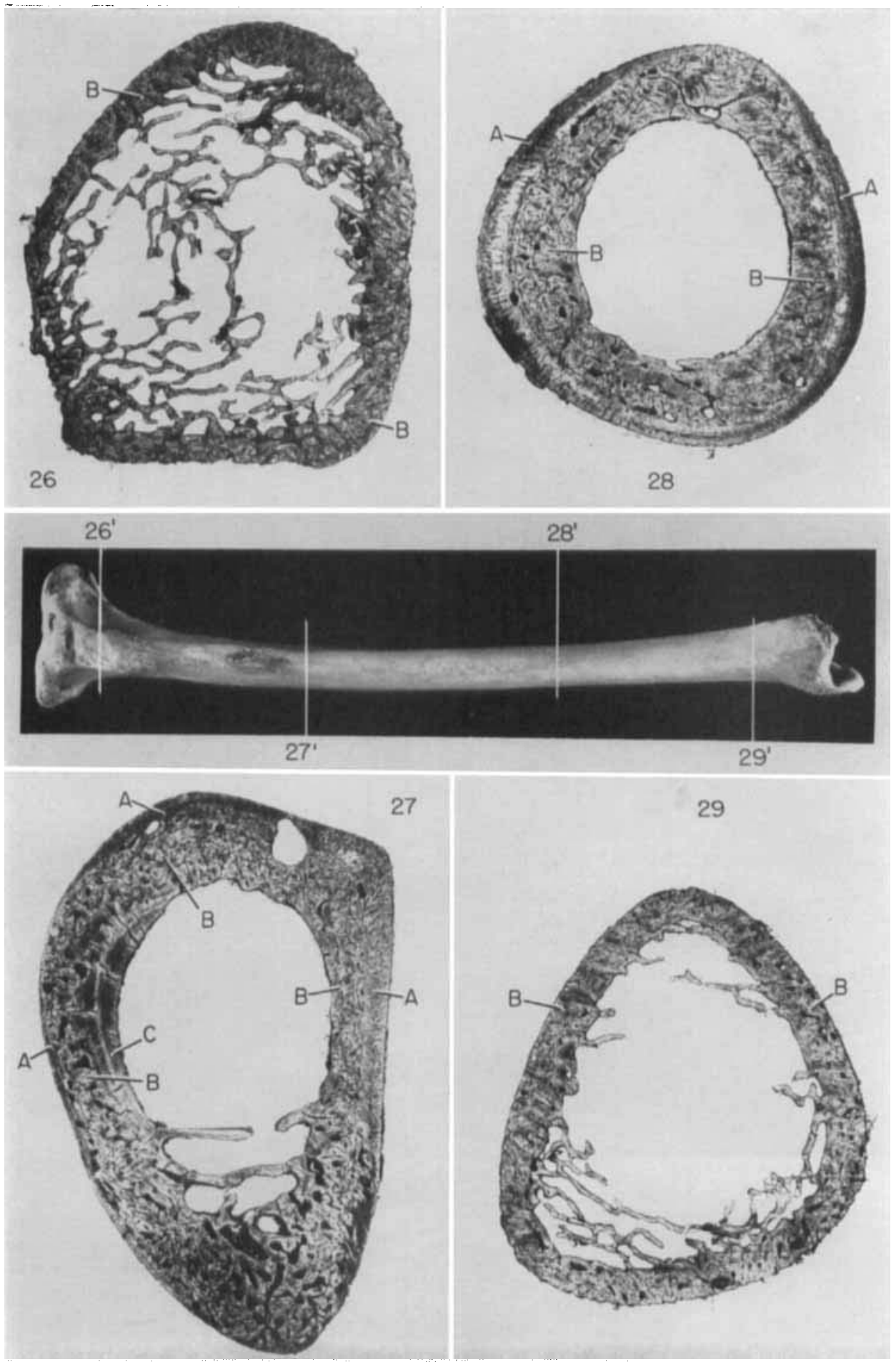